\title{
RETRACTED ARTICLE: Quaternary Ammonium and Phosphonium Based Deep Eutectic Solvents for the Solution-Based Exfoliation of Graphene
}

\author{
M. H. Chakrabarti - S. Eslava • I. M. Al Nashef • \\ N. S. A. Manan - F. S. Mjalli • E. Saiz • N. P. Brandon • \\ P. V. Aravind • M. A. Hashim
}

Received: 23 January 2014/Accepted: 19 May 2014/Published online: 18 September 2014

(C) Springer Science+Business Media New York 2014

The Editors have retracted this article due to copyright issues with parts of Figure 4.

M. H. Chakrabarti · N. P. Brandon

Department of Earth Science and Engineering, Imperial College London, South Kensington, London SW7 2AZ, UK

M. H. Chakrabarti $(\bowtie) \cdot$ M. A. Hashim

Department of Chemical Engineering, Faculty of Engineering, University of Malaya,

50603 Kuala Lumpur, Malaysia

e-mail: mohammedharun77@yahoo.com

S. Eslava $\cdot$ E. Saiz

Centre for Advanced Structural Ceramics, Department of Materials, Imperial College London, London SW7 2AZ, UK

I. M. Al Nashef

Chemical Engineering Department, King Saud University, Riyadh 11421, Saudi Arabia

\section{N. S. A. Manan}

Department of Chemistry, Faculty of Science, University of Malaya, 50603 Kuala Lumpur, Malaysia

F. S. Mjalli

Petroleum \& Chemical Engineering Department, Sultan Qaboos University, Muscat 123, Oman

P. V. Aravind

Process and Energy Department, Delft University of Technology, Leeghwaterstraat 44, 2628 CA Delft, The Netherlands 